\title{
Modeling variability of the lactation curves of cows in automated milking systems
}

\author{
F. M. Masía, ${ }^{1,2 *}$ ㅇ. A. Lyons, ${ }^{3} \oplus$ M. Piccardi, ${ }^{2,4} \oplus$ M. Balzarini ${ }^{2,4} \oplus$ R. C. Hovey, ${ }^{5} \oplus$ and S. C. Garcia ${ }^{6} \oplus$ \\ ${ }^{1}$ Cátedra de Producción de Leche, Facultad de Ciencias Agropecuarias, Universidad Nacional de Córdoba, Córdoba 5000, Argentina \\ ${ }^{2}$ Consejo Nacional de Investigaciones Científicas y Técnicas, Córdoba 5000, Argentina \\ ${ }^{3}$ Intensive Livestock Industries, NSW Department of Primary Industries, Elizabeth Macarthur Agricultural Institute, Menangle NSW 2568 , Australia \\ ${ }^{4}$ Cátedra de Estadística y Biometría, Facultad de Ciencias Agropecuarias, Universidad Nacional de Córdoba, Córdoba 5000, Argentina \\ ${ }^{5}$ Department of Animal Science, University of California, Davis 95616 \\ ${ }^{6}$ Dairy Science Group, School of Life and Environmental Sciences, Faculty of Science, The University of Sydney, Camden NSW 2570 , Australia
}

\section{ABSTRACT}

Historically, cow selection criteria were developed for conventional milking systems that have regular milking intervals (MI). However, in automatic milking systems (AMS), there is variability in MI within and between cows. These sources of variability provide an opportunity to identify cows with high daily milk yield (DY) and long MI. An extended MI (longer than $16 \mathrm{~h}$ in pasture-based systems) has a negative effect on DY. Cows that tolerate extended MI and maintain high DY can be considered more efficient than cows with low DY and long MI, or with high DY but short MI, thereby improving robotic system use. Knowledge of the behavior and parameters of lactation curves of cows in AMS could help farmers to identify cows with a specific lactational phenotype. The objective of this study was to identify individual cows with high DY and long MI within herds, which could reflect increased tolerance to milk accumulation under AMS. A database containing records for 773,483 milking events for one year (July 2016--June 2017) from 4 pasture-based AMS farms was used. Lactation curves within each herd were fitted using several mixed models including fixed effects for the parameters of the lactation curve and random cow effects. Predicted curves of average DY according to parity (multiparous and primiparous) were obtained. The best linear unbiased prediction of the random cow effect allowed us to categorize lactations as having either high or low milk production. The median MI of each lactation was then used to categorize cows as having either short or long MI. Daily yield at the peak of lactation, days to peak and 305-d cumulative milk production were used to compare the effect of DY and

Received November 26, 2019

Accepted April 10, 2020.

*Corresponding editor: fmasia@agro.unc.edu.ar
MI categories, as well as the DY $\times$ MI interaction. Milk production by multiparous and primiparous cows with high DY and long MI was between 35 and $45 \%$ higher than that of the low DY and short MI. From all lactations analyzed, the incidence of animals with high DY and long MI across farms was $7.5 \%$. We have identified and quantified a new, AMS-specific, phenotype (the combination of a relatively higher DY with relatively longer MI) with potential to increase use of AMS units. Identifying more efficient animals should help generate new approaches for differential management and for selecting cows in AMS.

Key words: robotic system, milk yield, automatic milking farm, milking interval

\section{INTRODUCTION}

Since they were first introduced in the early 1990s, automatic milking systems (AMS) have been increasingly adopted on dairy farms across the world (de Koning, 2010; Barkema et al., 2015). Indeed, AMS offers the opportunity to reduce labor on dairy farms, increase daily milk yield (DY, defined as the cumulative milk production of individual milking events within a $24-\mathrm{h}$ period, in $\mathrm{kg}$ of milk/cow per day), and improve the lifestyle of dairy farmers (de Koning, 2011; Rodenburg, 2017). Maximal efficiency of AMS relies on voluntary and distributed attendance of cows to the milking unit throughout lactation. This voluntary attendance generates variation in milking intervals (MI, defined as the time period that elapses between 2 consecutive milking events for each cow, in hours). This variability in MI, both within and between cows, is logically greater for AMS cows than for cows managed in conventional milking systems (CMS), where MI remains relatively constant.

Variation in MI is affected by management and might also have an individual cow variance component (Løvendahl and Chagunda, 2011). In pasture-based 
Table 1. Automatic milking systems farms used for analysis

\begin{tabular}{llll}
\hline Farm & Country & Calving system $^{1}$ & Breed $^{2}$ \\
\hline 1 & Australia & Split & Holstein and crossbreds \\
2 & Australia & Year-round & Holstein and crossbreds \\
3 & New Zealand & Split & Holstein and crossbreds \\
4 & Chile & Split & Jersey \\
\hline
\end{tabular}

${ }^{1}$ Split $=$ calves in 2 or 3 distinct periods each year. If 2 , usually spring and autumn.

${ }^{2}$ Crossbreeds $=$ predominantly Holstein $\times$ Jersey.

AMS, MI above $16 \mathrm{~h}$ has been related to negative effects on milk yield (Lyons et al., 2013a) and udder health (Hammer et al., 2012). Achieving an optimal MI for all individual cows will ensure that milk secretion is not impaired, therefore maximizing individual production and minimizing any risk of negative effects on udder health (André et al., 2010). Given that cows managed in AMS store different amounts of milk in the udder, depending on MI, those with relatively high DY and relatively long MI could be considered more "efficient" (Molfino, 2018). A greater proportion of these animals within a herd could allow an increase in the volumes of milk harvested per robot (MHR, in $\mathrm{kg}$ of milk/robot per day) through an increased number of cows milked per robot.

Maximizing the amount of MHR, which is a function of the number of daily milkings and the amount of milk collected in each milking visit, is critical for maximizing farm revenue (Sonck and Donkers, 1995; Hyde and Engel, 2002; Salfer et al., 2017). In a study that monitored several pasture-based commercial AMS farms in Australia on a monthly basis throughout a whole year, Lyons and Kerrisk (2017) concluded that the average pasture-based AMS farm could increase MHR by up to $60 \%$. Identifying groups of cows that tolerate extended MI and still have high DY could be an opportunity to increase MHR.

Milk production can be described by modeling lactation curves (Ehrlich 2011), where adding random cow effects to these models provides a measure of variability among cows (Piccardi et al., 2017). Modeled lactation curves have been used to calculate milk production at the individual cow level using the peak DY, days to peak, and 305-d cumulative milk production as the estimated parameters (Bouallegue et al., 2015). To date, most of the proposed statistical models have fitted lactation curves for cows in CMS (Piccardi et al., 2017; Kong et al., 2017) although the development of these predictions for AMS is scarce. We hypothesized that variability among cows in lactation curve parameters could be used to identify and monitor a new AMSspecific phenotype, first described by Molfino (2018), as the combination of relatively greater DY with relatively longer MI.
The objectives of the present study were to (a) estimate lactation curve parameters for cows milked in AMS and (b) assess the potential of using these parameters to describe individual cows with contrasting DY and MI as a means to identifying cows that are more "efficient" in AMS.

\section{MATERIALS AND METHODS}

\section{Data}

Data from 4 commercial pasture-based AMS farms, 2 in Australia, 1 in New Zealand, and 1 in Chile, were used in this study. The farms covered different dairy regions, calving systems, breeds, and herd sizes (Table 1).

The study was conducted using a database containing 773,483 individual milking records for one year (July 2016-June 2017) from the aforementioned farms as part of a study that captured key performance indicators related to AMS utilization on commercial farms (for full details, refer to Lyons and Kerrisk, 2017). The data set comprised a total of 790 lactations, all longer than DIM. Each record included date, farm number, cow number, and lactation, as well as DIM, MI, and milk yield defined as the milk production of an individual milking events, in $\mathrm{kg}$ of milk/cow per milking). Milk yield was used to calculate DY. Records with MI less than $1 \mathrm{~h}$ and greater than $24 \mathrm{~h}$ were removed from analysis as this generally indicated animals temporarily removed from the herd (commonly for health-related reasons) or missing data (lost data during system failure, such as a power interruption). This criterion removed $0.2 \%$ of the data available for analysis.

\section{Statistical Analysis}

Lactation curves for every lactation of every cow within every farm were fitted using 3 nonlinear functions, namely incomplete gamma function (Wood, 1967), the MilkBot model (Ehrlich, 2011), and diphasic model (Grossman and Koops, 1988). In every case, the outcome was DY. In the fixed part of the model, DY was explained as a function of DIM. Given that observations were expected to be temporarily auto- 
correlated within lactation, a random cow effect was added to a lactation curve parameter in the model. The models were fitted using the PROC NLMIXED procedure in SAS 9.4 (SAS Institute Inc., Cary, NC) with the direct likelihood approach as the estimated method. Lactations were analyzed separately for parity, as either primiparous or multiparous cows, where the second lactations were discarded given they showed an intermediate behavior, as suggested by Dematawewa et al. (2007). For model selection, Akaike information criterion (Sakamoto et al., 1986) and Bayesian information criterion (Schwarz, 1978) were used. The lactation parameters identified as production at peak of lactation (Ppeak), days to peak (Dpeak), and 305-d cumulative milk production (305-DY) were then obtained for each cow (lactation).

The incomplete gamma function, mixed Wood model, was selected as the best fit, yielding the equation

$$
Y(t)=(a+u)^{b} \exp ^{(-c t)},
$$

where $Y(t)$ is milk yield on day $t$ of lactation, $a$ is the parameter representing production at the beginning of lactation, and $u$ is the random effect; parameters $b$ and $c$ are associated with the increase and decrease of the slopes of the lactation curve, respectively.

The 305-DY was defined as the cumulative milk production from d 1 to 305 of the lactation period and was calculated using the integral of the fitted lactation curves:

$$
305 D Y=\int_{0}^{305}(a+u)^{b} \exp ^{(-c t)} d Y
$$

The random component added to the intercept was assumed to be normally distributed with zero mean and variance $\sigma_{a}^{2}$, which should be interpreted as an unobservable variable that represents a random deviation of the coefficient $a$ of the $i$ th lactation from the popula- tion parameter. Such random deviation is assumed to be independent of the error term. Thus, BLUP (Davidian and Giltinan, 2003) was obtained to identify animals with high, medium, or low DY (upper, medium, or lower tertile of the DY distribution, respectively).

The median MI was obtained for cows within each lactation on a given farm and was used to identify animals with relatively long, medium, and short MI (upper, medium, or lower tertile of the MI distribution, respectively).

An ANOVA model was then fitted for each lactation curve parameter to evaluate the effect of contrasting (high vs. low) DY category, MI category, and their interaction, treating the primiparous and multiparous cows separately. The category of low DY with short MI was established as a reference group for comparisons.

\section{RESULTS}

\section{Milking Interval and Daily Milk Yield}

Analysis of data from all 4 farms established that multiparous cows in the low and high DY tertiles had MI that were 10 and $14 \mathrm{~h}$, and DY that were 20.1 and $27.2 \mathrm{~kg}$ milk/day, respectively. Similarly, primiparous cows in the low and high DY tertiles had MI that were 11 and $14 \mathrm{~h}$, and DY that were 15.1 and $20.7 \mathrm{~kg}$ of milk/day, respectively (Table 2 ).

\section{Characterization of the Lactation Curve Estimation}

The Wood model fitted the individual lactation curves better than the other 2 models (smaller Akaike information criteria in more than the $70 \%$ of the fittings, Supplemental Table S1, https://doi.org/0.3168/ jds.2019-17962). Average estimates of the Wood model parameters for primiparous and multiparous cows are shown in Table 3. Furthermore, estimates of the Wood model parameters for lactation curves of primiparous and multiparous cows within each farm are shown in

\begin{tabular}{|c|c|c|c|c|c|c|}
\hline Parity & Farm & Short MI, h & Long MI, h & Low DY, kg/d & High DY, kg/d & No. of lactations \\
\hline \multirow{5}{*}{ Primiparous } & 1 & $10 \pm 0.24$ & $12 \pm 0.26$ & $22.2 \pm 0.27$ & $28.9 \pm 0.26$ & 138 \\
\hline & 2 & $11 \pm 0.24$ & $14 \pm 0.30$ & $15.6 \pm 0.29$ & $20.8 \pm 0.35$ & 90 \\
\hline & 3 & $12 \pm 0.18$ & $14 \pm 0.19$ & $13.0 \pm 0.27$ & $19.4 \pm 0.35$ & 27 \\
\hline & 4 & $11 \pm 0.22$ & $14 \pm 0.34$ & $9.8 \pm 0.20$ & $14.0 \pm 0.27$ & 59 \\
\hline & Average & $11 \pm 0.23$ & $14 \pm 0.30$ & $15.1 \pm 0.25$ & $20.7 \pm 0.31$ & 79 \\
\hline \multirow[t]{5}{*}{ Multiparous } & 1 & $10 \pm 0.22$ & $15 \pm 0.26$ & $28.4 \pm 0.50$ & $36.8 \pm 0.59$ & 239 \\
\hline & 2 & $11 \pm 0.22$ & $15 \pm 0.28$ & $18.1 \pm 0.36$ & $24.4 \pm 0.47$ & 141 \\
\hline & 3 & $9 \pm 0.21$ & $12 \pm 0.20$ & $18.8 \pm 0.45$ & $25.8 \pm 0.49$ & 42 \\
\hline & 4 & $10 \pm 0.22$ & $12 \pm 0.23$ & $15.4 \pm 0.35$ & $21.8 \pm 0.44$ & 54 \\
\hline & Average & $10 \pm 0.22$ & $14 \pm 0.26$ & $20.1 \pm 0.43$ & $27.2 \pm 0.53$ & 119 \\
\hline
\end{tabular}

Table 2. Average and SE lower and upper tertile of daily milk yield (DY) and milking interval (MI) for parity and farm ${ }^{1}$

${ }^{1}$ Short MI = lower tertile of MI; Long MI = upper tertile of MI; Low DY = lower tertile of DY; High DY = upper tertile of DY. 
Table 3. Estimates of the Wood model parameters (mean $\pm \mathrm{SE}$ ) for primiparous and multiparous cows for all herds ${ }^{1}$

\begin{tabular}{|c|c|c|c|c|c|c|}
\hline Parity & $a$ & $b$ & $c$ & Ppeak, kg/d & Dpeak, d & $305-\mathrm{DY}, \mathrm{kg}$ \\
\hline Primiparous & $10.27 \pm 0.58$ & $0.23 \pm 0.01$ & $0.0044 \pm 0.0002$ & $19.3 \pm 1$ & $53 \pm 2$ & $4,590 \pm 194$ \\
\hline Multiparous & $18.56 \pm 0.43$ & $0.24 \pm 0.01$ & $0.0053 \pm 0.0001$ & $34.8 \pm 1$ & $44 \pm 1$ & $7,752 \pm 158$ \\
\hline
\end{tabular}

${ }^{1} a=$ parameter $a$ of the Wood model; $b=$ parameter $b$ of the Wood model; $c=$ parameter $c$ of the Wood model; Ppeak = production at peak; Dpeak $=$ days to peak; cumulative milk production at $305 \mathrm{~d}$ of lactation.

Table 4. The value of parameter $a$ of the model that describes the milk yield at the beginning of the lactation, was smaller for primiparous than for multiparous cows in all farms. There were differences between primiparous and multiparous cows within farms for parameter $b$ of the model, which affect the slope of the curve from the beginning of lactation until it reaches its peak. The decline in production after the peak, expressed by parameter $c$ of the model, was greater for multiparous than for primiparous cows (Table 3). On average, the Ppeak for multiparous cows was $15.5 \mathrm{~kg}$ of milk/day higher than for primiparous cows and occurred almost $10 \mathrm{~d}$ earlier. Moreover, the 305-DY for primiparous was on average $59 \%$ of that for multiparous cows.

\section{Production at Peak, Days to Peak, and 305-DY Cumulative Milk Production}

On average, low DY primiparous cows had lower Ppeak than high DY primiparous cows $(P<0.05)$. Furthermore, the comparison of contrasting MI groups revealed a significant effect on Ppeak within high DY first-lactation cows. For primiparous cows, the greatest difference ( $8.1 \mathrm{~kg}$ of milk/day) was between the high DY/short MI and the reference group (animals with low DY and short MI) (Table 5).

Low DY multiparous cows had a lower Ppeak than the high DY multiparous cows $(P<0.05)$. Furthermore, for multiparous cows the contrasting MI groups within the DY group had no effect on Ppeak.

Neither DY nor MI within parity had an effect on Dpeak. On average, primiparous peaked at 53 DIM, whereas multiparous cows peaked at 40 DIM (Table 5).
First-lactation cows with high DY and either short or long MI produced 59 and $45 \%$ more 305-DY than low DY primiparous cows (Table 5), respectively. Multiparous cows with high DY and short MI produced $38 \%$ more 305-DY than the reference group, whereas multiparous cows with high DY and long MI produced $35 \%$ more 305-DY than the reference group (Table 5). There was no statistical difference in 305-DY for primiparous and multiparous cows with low DY and either short or long MI $(P<0.05)$.

\section{Grouping of Lactations}

The clustering of lactations according to DY and MI showed that 12.37 and $19.62 \%$ of all lactations had high DY and short MI for primiparous and multiparous cow respectively, whereas 6.72 and $8.33 \%$ of the lactations had high DY and long MI (Table 5). Moreover, Figure 1 shows estimated lactation curves of primiparous and multiparous cows according to production level and length of MI.

\section{DISCUSSION}

A key objective of this study was to estimate lactation curve parameters for pasture-based AMS cows, because these parameters had primarily been estimated for cows in CMS. As validation of our approach, we determined values for Ppeak and Dpeak that were similar to those previously reported (Cole et al., 2011; Piccardi et al., 2017). Differences in the parameter between primiparous and multiparous cows were also repeated, in general, among AMS farms when compared with pub-

Table 4. Parameter estimates of the Wood model (mean $\pm \mathrm{SE}$ ) for primiparous and multiparous cows for herds ${ }^{1}$

\begin{tabular}{|c|c|c|c|c|c|c|c|}
\hline Farm & Category & $a$ & $b$ & $c$ & Ppeak, kg/d & Dpeak, d & 305-DY, kg \\
\hline 1 & Multiparous & $18.35 \pm 0.48$ & $0.27 \pm 0.01$ & $0.0051 \pm 0.0001$ & $38.8 \pm 0.6$ & $52.2 \pm 0.9$ & $8,929 \pm 132$ \\
\hline 2 & Primiparous & $12.79 \pm 0.69$ & $0.18 \pm 0.01$ & $0.0044 \pm 0.0003$ & $20.8 \pm 0.9$ & $43.0 \pm 2.2$ & $4,833 \pm 227$ \\
\hline \multirow[t]{2}{*}{3} & Primiparous & $11.07 \pm 1.65$ & $0.23 \pm 0.03$ & $0.0055 \pm 0.0004$ & $20.1 \pm 1.9$ & $42.0 \pm 4.0$ & $4,372 \pm 400$ \\
\hline & Multiparous & $21.15 \pm 1.00$ & $0.14 \pm 0.01$ & $0.0044 \pm 0.0002$ & $29.7 \pm 0.6$ & $32.0 \pm 2.4$ & $6,549 \pm 139$ \\
\hline 4 & Primiparous & $6.68 \pm 0.74$ & $0.25 \pm 0.03$ & $0.0041 \pm 0.0003$ & $13.6 \pm 1.1$ & $59.5 \pm 4.5$ & $3,346 \pm 265$ \\
\hline
\end{tabular}

${ }^{1} a=$ parameter $a$ of the Wood model; $b=$ parameter $b$ of the Wood model; $c=$ parameter $c$ of the Wood model; Ppeak $=$ production at peak; Dpeak = days to peak; cumulative milk production at $305 \mathrm{~d}$ of lactation. 
lished values. The farms enrolled in the current study milked Holstein, Jersey, and crossbreed (predominantly Holstein $\times$ Jersey) cows. Although the aim of this study was not to look at the effect of breed in variation of MI, previous research has found that breed could have an effect in voluntary cow movement (Clark et al., 2014).

Understanding cow lactation curve dynamics, either individually or as a population, provides some of the key decision-making principles on commercial dairy farms (Macciotta et al., 2005). Moreover, it is possible to make inferences about management and physiology using values derived from a model that can then be used to monitor herd performance (Ehrlich, 2013). Parameters of the curves revealed that primiparous cows' milk yield at peak lactation represented $55.5 \%$ of the production by multiparous cows, which is lower than the $75 \%$ (Bailey and Currin, 2009) industry standards that have been recommended. This observation supports the findings of Siewert et al. (2019).

The exact reason behind the underperformance of primiparous cows cannot be determined from this study. Previous studies have reported sparse training of first-lactation cows to the AMS before the first milking with the robot (Tse et al., 2018). Moreover, primiparous cows visit the AMS less frequently than multiparous cows in early lactation (Siewert et al., 2019). Further investigation into milking frequency of primiparous cows, particularly in early lactation, would be warranted. Implementing practices such as pre-calving training, or managing first-lactation cows separately over the first part of the lactation could increase their milking frequency and therefore DY.

Parity has a strong influence on milk production, as primiparous cows have lower feed intake, and less udder and total secretory tissue than mature cows (Akers, 2017; Connor et al., 2019). In addition, first-lactation cows are still growing and therefore partition part of their nutrient intake toward growth (Wathes et al., 2007). As a result, milk production increases with lactation number (Vijayakumar et al., 2017).

Criteria for cow selection has been traditionally based on data from CMS, where cows have a relatively regular MI. Geneticists predominantly focus on the BLUP methodology to select cows with high DY, even with data from only a single lactation. Primiparous cow performance for several traits, but not MI, has been found to be an efficient selection criterion under CMS (Meyer, 1983). Nixon et al. (2009), calculated heritability for daily milking frequency and DY under AMS with primiparous Holstein cows, reporting values that ranged from 0.02 to 0.08 and 0.14 to 0.20 , respectively. Identifying and recognizing efficient animals in AMS could be achieved by monitoring DY and MI. Thus, another key objective of this study was to use lactation curve modeling to identify animals with high DY and long MI to increase utilization of AMS unit. Only a relatively small proportion $(6.72$ and $8.33 \%$ for primiparous and multiparous cows, respectively) appeared

Table 5. Parameter estimates of lactation curves according to cow production level (DY) and length of the milking interval (MI) ${ }^{1}$

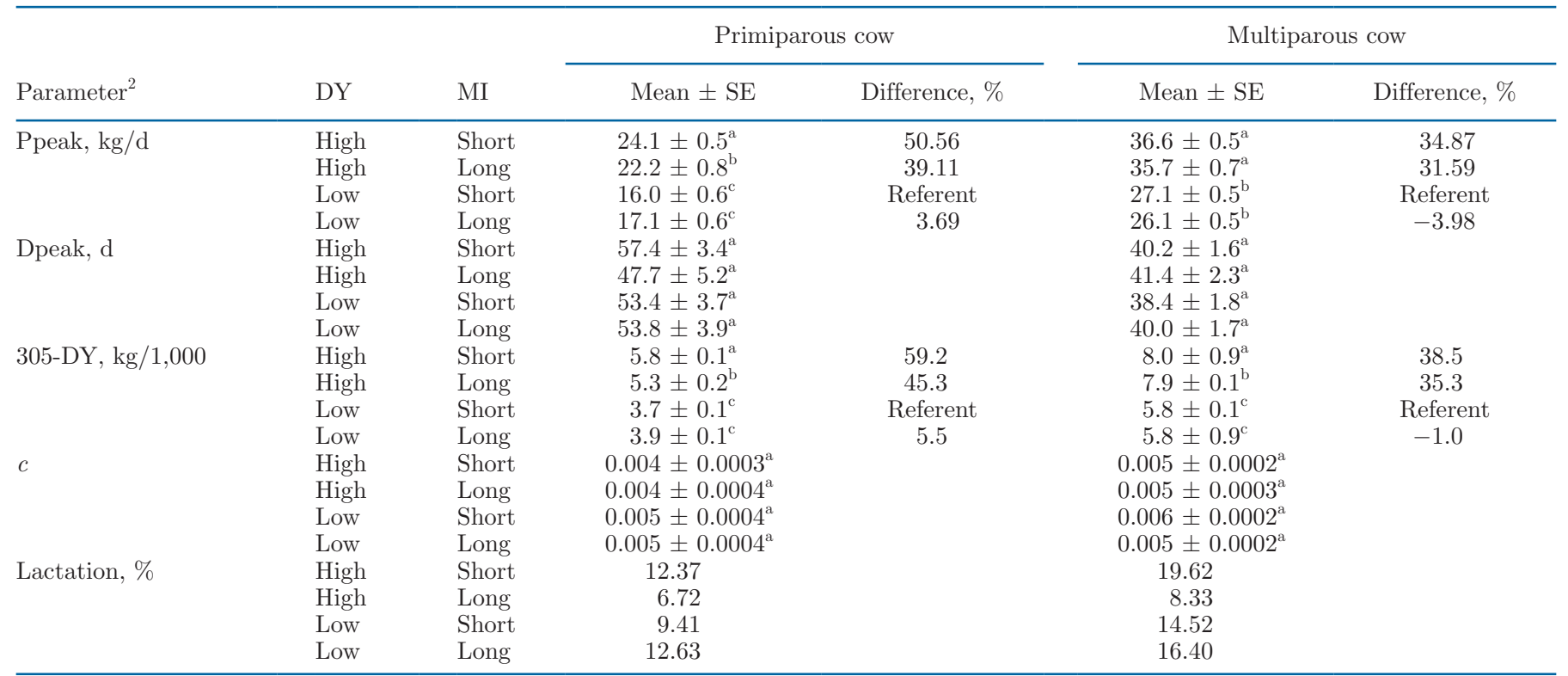

\footnotetext{
${ }^{\mathrm{a}-\mathrm{c}}$ Means with a different letter within a parameter and parity are statistically different $(P<0.05)$.

${ }^{1}$ Differences with respect to the reference group (in percentage). Positive and negative values indicate increases and decreases, respectively. ${ }^{2}$ Ppeak $=$ daily milk yield at peak; Dpeak $=$ days to peak; 305-DY $=305$-d cumulative milk production; $c=$ parameter $c$ of the Wood model; Lactation $=$ percentage of total lactations.
} 
$\mathrm{A}$

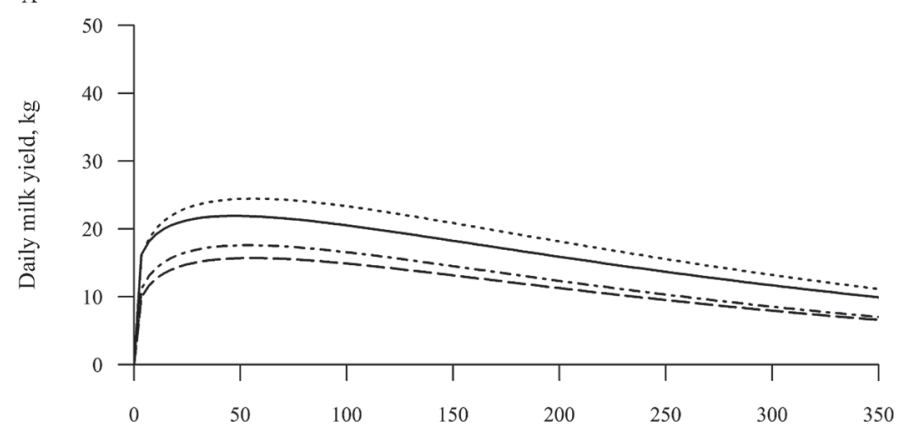

B

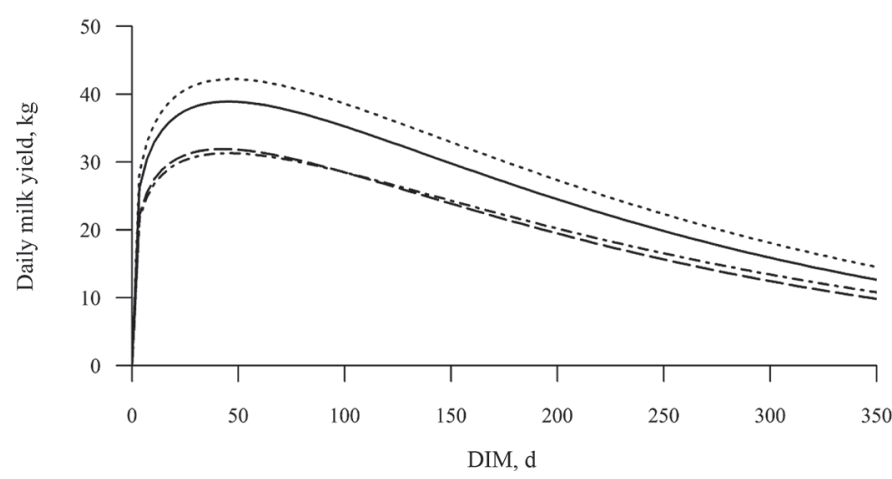

Figure 1. Estimated lactation curves according to production level (daily yield, DY) and length of the milking interval (MI) for primiparous (A) and multiparous cows (B). Dotted line $=$ high DY and short MI; solid line = high DY and long MI; dashed line = low DY and short MI; dotted-dashed line = low DY and long MI.

to have this phenotype. Molfino (2018) reported similar results (10.5\% of cows with high DY and long MI) using linear mixed models to determine the effect of stage of lactation and parity and to obtain predicted means and residuals for the 2 traits. Further studies are needed to quantify the genetic component of MI within AMS.

Furthermore, compared with the reference groups, the high DY and long MI groups produced $45 \%$ and $35 \%$ more across their whole lactation, for primiparous and multiparous cows, respectively. Several factors might explain how these animals sustained higher DY with longer MI. At the anatomical level, high DY/long MI animals may have a greater ability to store or drain secreted milk from alveoli due to a greater cisternal volume within their udder (Knight and Dewhurst, 1994; Stelwagen and Knight, 1997). Indeed, the ability of the udder to withstand production losses due to once-daily milking reflects this capacity of alveolar milk to drain to the cistern (Davis et al., 1998). The fact that there is a genetic basis for the size of the cisternal and alveolar compartments raises the prospect of selecting animals for these characteristics (Davis et al., 1998). Additionally, high DY/long MI animals may be less sensitive to local negative feedback cues in cu- mulative milk, including molecules such as serotonin, or physical changes including alveolar distension and cellular stretch (Weaver and Hernandez, 2016). The current data were from pastured-based cows producing a relatively low amount of milk, and typically managed under a 3-way grazing system (Lyons et al., 2013a; 2013b). Whether our findings apply to cows milked by AMS in confinement operations with higher per-cow milk production remains to be tested. More research with larger data sets comprising whole life productivity of animals would also help to address this question.

The ability to segregate high DY/long MI animals based on modeled production data presents a unique opportunity to further resolve the phenotypic and genetic bases for a greater tolerance to longer MI. This same approach could be used to identify primiparous/ multiparous cows that visit the AMS more frequently in early lactation that might then lead to a sustained increase in production for the entire lactation, as has been reported for CMS (Wall and McFadden, 2012).

The number of cows milked per robot per day is one of the greatest drivers of overall system performance (Castro et al., 2012; Molfino, 2018). Our findings could also be used to improve management practices, including animal selection criteria, which could improve the economic viability of AMS. In this sense, approaches to increase DY have been made by milking existing cows more often (Stockdale, 2006), although this strategy may negatively affect overall efficiency and should be evaluated at the farm level. Within the present data set, if $11 \%$ of lactations belonging to the low DY/short MI group (reference group, the worst performing) were replaced by animals similar to those in the $7 \%$ of lactations in the high DY/long MI group, then a theoretical $24 \%$ increase in production at the farm level could be achieved. This assumption is similar to results reported by Molfino (2018) who, using a different approach to identify efficient (high DY/long MI) cows in AMS, estimated a theoretical increase in milk yield of 13 to $24 \%$ if the whole herd was composed of "efficient" cows. Moreover, our findings indicate that with animal selection/discrimination, the same number of cows could potentially be managed with fewer robots. Considering that the initial investment required to install AMS has a marked effect on profitability (Salfer et al., 2017), such a strategy could make the investment more attractive.

Cows in the upper tertile for both DY and MI had greater production with fewer visits to the AMS per day, making them readily identifiable as more efficient in terms of MHR. Although these cows produced less milk across the entire lactation compared with cows with a high DY and short MI, their total number of visits to the robot per day was lower. Although MI 
affects the time each animal spends in the robot, it is expected that the reduction in visits would compensate for the increase in time spent in the milking unit at each visit. In our study, cows in the short and long MI groups had 10 and $14 \mathrm{~h}$ between milkings, respectively. In Australian pasture-based farms using AMS, the average occupancy is 51 cows per robot per day (Lyons and Kerrisk, 2017). If these efficiency gains at a milkingtime level were achieved, a longer MI would enable the same robot to be used by more animals. Despite high DY/long MI cows producing less milk than high DY/ short MI cows, this loss would be compensated by the potential increase in the number of animals that could be milked per robot per day. Even though it has been reported that extended MI, particularly above $16 \mathrm{~h}$, reduced daily milk production (Lyons et al., 2013a) and increased the risk of mastitis (Hammer et al., 2012), not all animals are expected to be affected in the same way, because subject-specific responses are highly conditioned to individual abilities. André et al. (2010) reported a wide variation between individual cows in the effect of interval length on daily DY. By improving the use of each AMS and increasing MHR, profitability of the operation should increase (Jago and Burke, 2010).

\section{CONCLUSIONS}

We have described a statistical modeling approach to successfully identify and quantify a new, AMS-specific phenotype namely lactating animals with relatively greater DY and relatively longer MI than the average cow. Our results show that $\sim 7 \%$ of cows in AMS farms produce more milk with fewer milkings than average. More research is needed to analyze between-cow variability in voluntary attendance to the automatic milking facilities during early, middle, and late lactation, and its correlation with production over the entire lactation. Identifying cows with high DY and long MI could allow differential management practices and rules to be developed for cows of contrasting "AMS efficiency." Future selection for this new AMS-specific phenotype could result in an increased number of animals milked per robot, which represents an opportunity to increase the MHR, improving the profitability of the system. This could make future adoption of technology in pasture-based AMS more attractive.

\section{ACKNOWLEDGMENTS}

The authors thank the farmers for their willingness to participate in this project, as well as for their time and assistance during the data collection period. The project was part of the Priority Partnership Collaboration Awards between The University of Sydney and
University of California, Davis. The first author is the recipient of a Postgraduate Research Scholarship from Consejo Nacional de Investigaciones Científicas y Técnicas. The researchers express their gratitude to NSW Department of Primary Industries (New South Wales, Australia) for providing the dataset. The authors have not stated any conflicts of interest.

\section{REFERENCES}

Akers, R. M. 2017. A 100-year review: Mammary development and lactation. J. Dairy Sci. 100:10332-10352. https://doi.org/10.3168/ jds.2017-12983.

André, G., P. B. M. Berentsen, B. Engel, C. J. de Koning, and A. G. J. M. Oude Lansink. 2010. Increasing the revenues from automatic milking by using individual variation in milking characteristics. J. Dairy Sci. 93:942-953. https://doi.org/10.3168/jds.2009-2373.

Bailey, T., and J. Currin. 2009. Milk production evaluation in first lactation heifers. Virginia Cooperative Extension, Virginia Tech and Virginia State University. Accessed May 18, 2020. https:// www.pubs.ext.vt.edu/404/404-285/404-285.html.

Barkema, H. W., M. A. von Keyserlingk, J. P. Kastelic, T. J. Lam, C. Luby, J. P. Roy, S. J. LeBlanc, G. P. Keefe, and D. F. Kelton. 2015. Invited review: Changes in the dairy industry affecting dairy cattle health and welfare. J. Dairy Sci. 98:7426-7445. https://doi .org/10.3168/jds.2015-9377.

Bouallegue, M., R. Steri, N. M'hamdi, and M. Ben Hamouda. 2015. Modelling of individual lactation curves of Tunisian Holstein-Friesian cows for milk yield, fat, and protein contents using parametric, orthogonal and spline models. J. Anim. Feed Sci. 24:11-18. https://doi.org/10.22358/jafs/65648/2015.

Castro, A., J. M. Pereira, C. Amiama, and J. Bueno. 2012. Estimating efficiency in automatic milking systems. J. Dairy Sci. 95:929-936. https://doi.org/10.3168/jds.2010-3912.

Clark, C. E. F., N. B. P. Kwinten, D. A. J. M. van Gastel, K. L. Kerrisk, N. A. Lyons, and S. C. Garcia. 2014. Differences in voluntary cow traffic between Holstein and Illawarra breeds of dairy cattle in a pasture-based automatic milking system. Asian-Australas. J. Anim. Sci. 27:587-591. https://doi.org/10.5713/ajas.2013.13435.

Cole, J. B., D. J. Null, and A. De Vries. 2011. Short communication: Best prediction of 305-day lactation yields with regional and seasonal effects. J. Dairy Sci. 94:1601-1604. https://doi.org/10.3168/ jds.2010-3865.

Connor, E. E., J. L. Hutchison, C. P. Van Tassell, and J. B. Cole. 2019. Defining the optimal period length and stage of growth or lactation to estimate residual feed intake in dairy cows. J. Dairy Sci. 102:6131-6143. https://doi.org/10.3168/jds.2018-15407.

Davidian, M., and D. M. Giltinan. 2003. Nonlinear models for repeated measurement data: An overview and update. J. Agric. Biol. Environ. Statstics. 8:387-419. https://doi.org/10.1198/1085711032697.

Davis, S. R., V. C. Farr, P. J. A. Copeman, V. R. Carruthers, C. H. Knight, and K. Stelwagen. 1998. Partitioning of milk accumulation between cisternal and alveolar compartments of the bovine udder: relationship to production loss during once daily milking. J. Dairy Res. 65:1-8. https://doi.org/10.1017/S0022029997002562.

de Koning, C. J. A. M. 2010. Automatic milking: Common practice on dairy farms. Pages 59-63 in Proceedings 2nd North Am. Conf. Robotic Milking, Toronto, Canada. Precision Dairy Operators, Elora, Canada.

de Koning, K. 2011. Automatic milking: Common practice on over 10,000 dairy farms worldwide. Pages 14-31 in Proceedings of Dairy Research Foundation Symposium 2011. The University of Sydney, Camden, Australia, Camden, NSW, Australia. P. Celi, ed University Printing Services Sydney, Sydney, Australia.

Dematawewa, C. M. B., R. E. Pearson, and P. M. VanRaden. 2007. Modeling extended lactations of Holsteins. J. Dairy Sci. 90:39243936. https://doi.org/10.3168/jds.2006-790. 
Ehrlich, J. L. 2011. Quantifying shape of lactation curves, and benchmark curves for common dairy breeds and parities. Bov. Pract. 45:88-95.

Ehrlich, J. L. 2013. Quantifying inter-group variability in lactation curve shape and magnitude with the MilkBot lactation model PeerJ 1:e54. https://doi.org/10.7717/peerj.54.

Grossman, M., and W. J. Koops. 1988. Multiphasic analysis of lactation curves in dairy cattle. J. Dairy Sci. 71:1598-1608. https://doi .org/10.3168/jds.S0022-0302(88)79723-4.

Hammer, J. F., J. M. Morton, and K. L. Kerrisk. 2012. Quarter-milking-, quarter-, udder- and lactation-level risk factors and indicators for clinical mastitis during lactation in pasture-fed dairy cows managed in an automatic milking system. Aust. Vet. J. 90:167174. https://doi.org/10.1111/j.1751-0813.2012.00917.x.

Hyde, J., and P. Engel. 2002. Investing in a robotic milking system: A Monte Carlo simulation analysis. J. Dairy Sci. 85:2207-2214. https://doi.org/10.3168/jds.S0022-0302(02)74300-2.

Jago, J., and J. Burke. 2010. An evaluation of two pastoral dairy production systems using automatic milking technology. Pages 109-116 in Proceedings of the New Zealand Grassland Association 72, Christchurch, New Zealand.

Knight, C. H., and R. D. Dewhurst. 1994. Once daily milking of dairy cows: Relationship between yield loss and cisternal milk storage. J. Dairy Res. 61:441-449. https://doi.org/10.1017/ S0022029900028363.

Kong, L.-N., J.-B. Li, R.-L. Li, X.-X. Zhao, Y.-B. Ma, S.-H. Sun, J.-M. Huang, Z.-H. Ju, M.-H. Hou, and J.-F. Zhong. 2018. Estimation of 305-day milk yield from test-day records of Chinese Holstein cattle. J. Appl. Anim. Res. 46:791-797. https://doi.org/10.1080/ 09712119.2017.1403918.

Løvendahl, P., and M. G. G. Chagunda. 2011. Covariance among milking frequency, milk yield, and milk composition from automatically milked cows. J. Dairy Sci. 94:5381-5392. https://doi.org/10 $.3168 /$ jds.2010-3589.

Lyons, N. A., and K. L. Kerrisk. 2017. Current and potential system performance on commercial automatic milking farms. Anim. Prod. Sci. 57:1550-1556. https://doi.org/10.1071/AN16513.

Lyons, N. A., K. L. Kerrisk, N. K. Dhand, and S. C. Garcia. 2013a. Factors associated with extended milking intervals in a pasturebased automatic milking system. Livest. Sci. 158:179-188. https:/ /doi.org/10.1016/j.livsci.2013.10.010.

Lyons, N. A., K. L. Kerrisk, and S. C. Garcia. 2013b. Comparison of 2 systems of pasture allocation on milking intervals and total daily milk yield of dairy cows in a pasture-based automatic milking system. J. Dairy Sci. 96:4494-4504. https://doi.org/10.3168/ jds.2013-6716.

Macciotta, N. P. P., D. Vicario, and A. Cappio-Borlino. 2005. Detection of different shapes of lactation curve for milk yield in dairy cattle by empirical mathematical models. J. Dairy Sci. 88:11781191. https://doi.org/10.3168/jds.S0022-0302(05)72784-3.

Meyer, K. 1983. Scope for evaluating dairy sires using first and second lactation records. Livest. Prod. Sci. 10:531-553. https://doi.org/10 .1016/0301-6226(83)90048-9.

Molfino, J. 2018. Investigation into system and cow performance efficiency in pasture-based automatic milking systems. $\mathrm{PhD}$ Thesis. Faculty of Science. School of Life and Environmental Sciences, The University of Sydney, Camden, Australia.

Nixon, M., J. Bohmanova, J. Jamrozik, L. R. Schaeffer, K. Hand, and F. Miglior. 2009. Genetic parameters of milking frequency and milk production traits in Canadian Holsteins milked by an automated milking system. J. Dairy Sci. 92:3422-3430. https://doi .org/10.3168/jds.2008-1689.

Piccardi, M., R. Macchiavelli, A. C. Funes, G. A. Bó, and M. Balzarini. 2017. Fitting milk production curves through nonlinear mixed models. J. Dairy Res. 84:146-153. https://doi.org/10.1017/ S0022029917000085.

Rodenburg, J. 2017. Robotic milking: Technology, farm design, and effects on work flow. J. Dairy Sci. 100:7729-7738. https://doi.org/ 10.3168/jds.2016-11715.

Sakamoto, Y., M. Ishiguro, and G. Kitagawa. 1986. Akaike Information Criterion Statistics. Springer, Dordrecht, the Netherlands.

Salfer, J. A., K. Minegishi, W. Lazarus, E. Berning, and M. I. Endres. 2017. Finances and returns for robotic dairies. J. Dairy Sci. 100:7739-7749. https://doi.org/10.3168/jds.2016-11976.

Schwarz, G. 1978. Estimating the dimension of a model. Ann. Stat. 6:461-464. https://doi.org/10.1214/aos/1176344136.

Siewert, J. M., J. A. Salfer, and M. I. Endres. 2019. Milk yield and milking station visits of primiparous versus multiparous cows on automatic milking system farms in the Upper Midwest United States. J. Dairy Sci. 102:3523-3530. https://doi.org/10.3168/jds .2018-15382.

Sonck, B. R., and H. W. J. Donkers. 1995. The milking capacity of a milking robot. J. Agric. Eng. Res. 62:25-37. https://doi.org/10 $.1006 /$ jaer.1995.1060.

Stelwagen, K., and C. H. Knight. 1997. Effect of unilateral once or twice daily milking of cows on milk yield and udder characteristics in early and late lactation. J. Dairy Res. 64:487-494. https://doi .org/10.1017/S0022029997002458.

Stockdale, C. R. 2006. Influence of milking frequency on the productivity of dairy cows. Aust. J. Exp. Agric. 46:965-974. https://doi .org/10.1071/EA05308.

Tse, C., H. W. Barkema, T. J. DeVries, J. Rushen, E. Vasseur, and E. A. Pajor. 2018. Producer experience with transitioning to automatic milking: Cow training, challenges, and effect on quality of life. J. Dairy Sci. 101:9599-9607. https://doi.org/10.3168/jds 2018-14662

Vijayakumar, M., J. H. Park, K. S. Ki, D. H. Lim, S. B. Kim, S. M. Park, H. Y. Jeong, B. Y. Park, and T. Kim. 2017. The effect of lactation number, stage, length, and milking frequency on milk yield in Korean Holstein dairy cows using automatic milking system. Asian-Australas. J. Anim. Sci. 30:1093-1098. https://doi.org/10 .5713 /ajas. 16.0882

Wall, E. H., and T. B. McFadden. 2012. Triennial lactation symposium: A local affair: How the mammary gland adapts to changes in milking frequency. J. Anim. Sci. 90:1695-1707. https://doi.org/ 10.2527/jas.2011-4790.

Wathes, D. C., Z. Cheng, N. Bourne, V. J. Taylor, M. P. Coffey, and S. Brotherstone. 2007. Differences between primiparous and multiparous dairy cows in the inter-relationships between metabolic traits, milk yield and body condition score in the periparturient period. Domest. Anim. Endocrinol. 33:203-225. https://doi.org/10.1016/j domaniend.2006.05.004.

Weaver, S. R., and L. L. Hernandez. 2016. Autocrine-paracrine regulation of the mammary gland. J. Dairy Sci. 99:842-853. https://doi .org/10.3168/jds.2015-9828.

Wood, P. D. P. 1967. Algebraic model of the lactation curve in cattle. Nature 216:164-165. https://doi.org/10.1038/216164a0.

\section{ORCIDS}

F. M. Masía @ https://orcid.org/0000-0001-9788-3695 N. A. Lyons @ https://orcid.org/0000-0002-7137-4937 M. Piccardi ㄷ https://orcid.org/0000-0001-8604-2540 M. Balzarini $\odot$ https://orcid.org/0000-0002-4858-4637 R. C. Hovey ๑i https://orcid.org/0000-0002-9834-253X S. C. Garcia (๑ https://orcid.org/0000-0002-2742-0262 